\title{
Microstructure and Mechanical Properties of Ti5553 Butt Welds Performed by LBW under Conduction Regime
}

\author{
Jose Maria Sánchez-Amaya ${ }^{1, *}$, Timotius Pasang ${ }^{2}$, Margarita Raquel Amaya-Vazquez ${ }^{1}$, \\ Juan De Dios Lopez-Castro ${ }^{1}$, Cristina Churiaque ${ }^{1}$, Yuan Tao ${ }^{2}$ and \\ Francisco Javier Botana Pedemonte ${ }^{1}$ \\ 1 Departmento de Ciencia de los Materiales e Ingeniería Metalúrgica y Química Inorgánica, LABCYP, \\ Universidad de Cádiz. Escuela Superior de Ingeniería, Av. Universidad de Cádiz, 11519 Puerto Real, Cádiz, \\ Spain; margarita.amaya@uca.es (M.R.A.-V.); juan.lopezcastro@uca.es (J.D.D.L.-C.); \\ cristina.churiaque@uca.es (C.C.); javier.botana@uca.es (F.J.B.P.) \\ 2 Department of Mechanical Engineering, AUT University, Auckland 1020, New Zealand; \\ timotius.pasang@aut.ac.nz (T.P.); yuan.tao@aut.ac.nz (Y.T.) \\ * Correspondence: josemaria.sanchez@uca.es; Tel.: +34-956-483-339
}

Received: 20 June 2017; Accepted: 10 July 2017; Published: 13 July 2017

\begin{abstract}
Ti-5Al-5V-5Mo-3Cr (Ti5553) is a metastable $\beta$ titanium alloy with a high potential use in the aeronautic industry due to its high strength, excellent hardenability, fracture toughness and high fatigue resistance. However, recent research shows this alloy has a limited weldability. Different welding technologies have been applied in the literature to weld this alloy, such as electron beam welding (EBW), gas tungsten arc welding (GTAW) or laser beam welding (LBW) under keyhole regime. Thus, in tensile tests, joints normally break at the weld zones, the strength of the welds being always lower than that of the base metal. In the present work, a novel approach, based on the application of LBW under conduction regime (with a High-Power Diode Laser, HPDL), has been employed for the first time to weld this alloy. Microstructure, microhardness and strength of obtained welds were analyzed and reported in this paper. LBW under conduction regime (LBW-CR) leads to welds with slightly higher values of Ultimate Tensile Strength (UTS) than those previously obtained with other joining processes, probably due to the higher hardness of the fusion zone and to lower porosity of the weld.
\end{abstract}

Keywords: laser beam welding; conduction regime; Ti-5Al-5V-5Mo-3Cr

\section{Introduction}

Titanium and its alloys have been used commercially in various industries since the 1950s. The industries that have taken the benefit of titanium range from automotive, jewelry, sporting equipment, petrochemical, marine, aerospace and, more recently, biomedical industry. The reasons behind the successful applications of titanium alloys in many industries include their (i) relatively low density (vs. steels and superalloys), (ii) excellent corrosion resistance (vs. steels), (iii) moderate-to-high strength (vs. aluminum), (iv) ability to withstand up to $600{ }^{\circ} \mathrm{C}$ (better than aluminum), and (v) compatibility with the human body. Titanium alloys are generally divided into three main families, the so-called $\alpha, \alpha+\beta$ and $\beta$ alloys. A great advantage of $\beta$ alloys is that they can be processed at lower temperatures than $\alpha+\beta$ alloys, and some heavily stabilized $\beta$ alloys are even cold deformable.

Depending on their classification, weldability of titanium may range from poor to excellent. Although commercially pure titanium, $\alpha$-titanium and $\alpha+\beta$ titanium generally have excellent weldability, metastable $\beta$ titanium alloys may have limited weldability due to the high content 
of $\beta$ stabilizing elements [1]. Metastable $\beta$ titanium alloys have good weldability in the annealed or solution heat-treated conditions [1]. In general, in the as-welded (AW) condition, the weld fusion zone (FZ) is comprised of coarse columnar $\beta$ grains from solidification while the heat-affected zone (HAZ) adjacent to the fusion lines is characterized by retained $\beta$ structure. In this condition, the strength and hardness of these welds are low, but their ductility is reasonable. Becker and Baeslack [2] conducted weldability studies on three different types of metastable $\beta$ titanium alloys (Ti-15V-3Cr-3Al-3Sn, Ti-8V-7Cr-3Al-4Sn-1Zr and Ti-8V-4Cr-2Mo-2Fe-3Al) and showed that the alloys are readily weldable. For all three alloys, the strengths were increased with post-weld heat treatment (PWHT) at, however, the expense of ductility. Weldability of Beta-21S sheet using laser welding technique was investigated by Liu et al. [3]. Both the FZ and HAZ were narrow with fine retained $\beta$ grain structure. The FZ was "crown-shaped" (also referred in the literature as "hour glass-shaped") with wider top and bottom surfaces compared with the mid-thickness area. Epitaxial grain growth was observed to form from the HAZ into the FZ. The FZ had transitioned from a solidification mode of a cellular-type along the fusion boundary to a complete cellular-dendritic (or columnar-dendritic) solidification mode at the weld centerline [3]. Welding investigations on Beta-CTM (metastable $\beta$ titanium alloy Ti-3Al-8V-6Cr-4Mo-4Zr, Ti 38-644) using Gas Tungsten Arc Welding (GTAW or TIG) showed epitaxial growth from the near-HAZ into the FZ, solidified with a cellular mode and progressively formed a complete columnar-dendritic grain structure at the weld centerline [4].

In the early 2000s, a new metastable $\beta$ titanium alloy known as Ti-5Al-5V-5Mo-3Cr, designated as Ti5553, was introduced. It is a variation of the alloy VT22, being an alternative to the Ti-10-2-3 alloy. The advantage of this alloy as compared to other $\beta$ titanium alloys is the sluggish precipitation kinetics of the $\alpha$ phase $[5,6]$. Ti5553 offers high strength, excellent hardenability, fracture toughness as well as high fatigue resistance [7]. The potential applications of this alloy are in the high-strength related areas such as landing gear and pylon/nacelle areas. Note that the landing gear beam truck of a Boeing 787 has been successfully manufactured using this alloy [8]. To find more applications in different areas, a number of factors have to be investigated, and one of them is the weldability.

The most common welding techniques to joint titanium and its alloys are Gas Metal Arc Welding (GMAW), such as Metal Inert Gas (MIG); Plasma Arc Welding (PAW); Laser Beam Welding (LBW); and Electron Beam Welding (EBW) [1,9-12]. The first three methods fall in the arc welding category with high heat input and low power density of heat source, while the last two techniques belong to the high-energy beam group.

LBW can be performed by two mechanisms: keyhole and conduction, the basic difference between two modes depending on the characteristics of the generated weld pool [13]. The key difference between these two operational regimes is the power density applied to the welding area. Conduction takes place when the energy intensity is not enough to provoke boiling, while in Keyhole, the intensity is sufficiently high to cause evaporation in the weld zone, creating a cavity (keyhole) in the melt pool [14]. A basic scheme of both operational modes is included in Figure 1. The energy density of the laser beam is higher in keyhole welding than in conduction welding, therefore leading to narrower weld beads. LBW under Keyhole Regime (LBW-KR) generates a cavity in the weld pool as a consequence of the metal evaporation. This cavity is stabilized by the pressure of the own vapor generated [15]. The keyhole is associated with violent plasma generation, which consists of metal vapor, ionized ions and electrons. The plasma resides both outside and inside the keyhole, known as the plasma plume and keyhole plasma, respectively [16]. The stability of the keyhole depends on a balance between surface tension pressure and vapor pressure: surface tension pressure tends to close the keyhole, while vaporization tends to keep it open $[17,18]$. Keyhole is reported to oscillate throughout the welding process and can lead to porosity defects in the final welds, especially in the case of partial penetration laser welding. Keyhole-induced porosity has been identified through experiments on the welding processes and is considered to be one of the major causes of porosity defects in laser welds. Large porosity defects can significantly deteriorate some of the mechanical properties of the welds, such as the tensile and fatigue strength [18]. Thus, Pang et al. [18] have 
developed a quantitative model able to predict the porosity defects induced by keyhole instability of titanium laser welding.
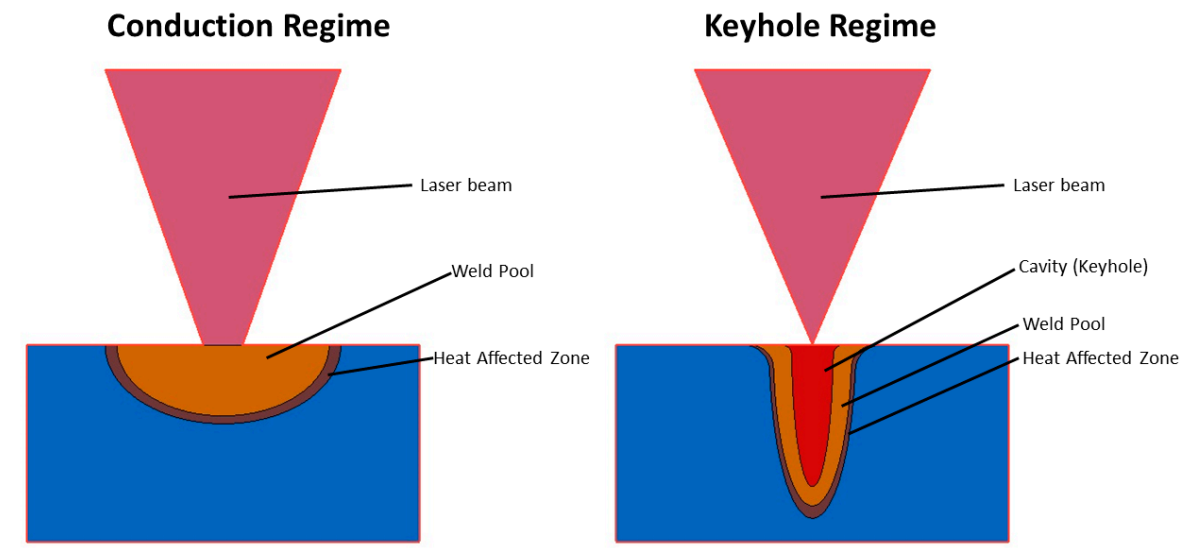

Figure 1. Schematic description of conduction and keyhole laser beam welding (LBW) regimes.

LBW under Keyhole Regime (LBW-KR) is more widely employed than LBW under Conduction Regime (LBW-CR), because it produces welds with high aspect ratios and narrow heat-affected zones $[19,20]$. On the other hand, LBW-CR is a more stable process, since metal vaporization occurs at a lower level than in LBW-KR $[16,17,21]$. In LBW-CR, the energy density of the laser beam locally heats the material up to a temperature above its melting point and below its boiling point [22]. Therefore, conduction welding offers an alternative joining mode for difficult-to-weld materials $[13,23]$, such as the Ti5553 alloy. In fact, LBW-CR is being nowadays investigated for different purposes, such as to confirm the simulation results. Thus, simulation studies were performed to understand the weld pool flow patterns of titanium, showing that laser weld pool flow dynamics play a key role during the transition from conduction mode to keyhole [24]. A model is presented by Du et al. [25] for flow simulation of full penetration laser beam welding of titanium alloy, concluding that the molten pool becomes shorter and wider under the conduction regime, as a consequence of the Marangoni effect. More recently, a Finite Element Method (FEM) has been successfully developed to simulate the LBW-CR of Ti6Al4V alloy, employing for the first time a heat source with a double ellipsoid shape [26]. An excellent agreement between these simulations and experimental welding results was found, allowing the use of the refined FEM model to predict phase transformations, distortion and stresses of LBW of industrial titanium elements [26]. On the other hand, LBW-CR have been also employed to study the influence of some experimental variables on the welding process, as the superficial pre-treatments, concluding that chemical cleaning pre-treatments led to deeper and stronger welds than those treatments based on coatings [27]. Conduction regime also offers the possibility to perform laser heat treatments at localized zones of pieces, in order to provoke improvements of some properties, such as hardness [28,29], corrosion resistance [28] or tribocorrosion behavior [30,31].

In the present work, LBW-CR (with a High-Power Diode Laser, HPDL) has been applied for the first time to weld the Ti5553 alloy. Microstructure, microhardness and strength of obtained welds have been reported. The obtained results have been compared with the microstructure and properties of Ti5553 welds obtained in the literature with other joining techniques, such as GTAW, EBW and LBW under keyhole regime.

\section{Materials and Methods}

In this investigation, a metastable $\beta$ titanium alloy, Ti-5Al-5V-5Mo-3Cr (Ti5553), was used. This alloy was provided by the Boeing Aircraft Company (Chicago, IL, USA). The alloy was in the annealed condition with a typical $\alpha / \beta$ microstructure. The chemical composition of the material is shown in Table 1. 
Table 1. Chemical composition (wt \%) of the Ti5553 alloy used in this study.

\begin{tabular}{ccccccccc}
\hline Material & $\mathbf{O}$ & $\mathbf{N}$ & $\mathbf{A l}$ & $\mathbf{V}$ & $\mathbf{M o}$ & $\mathbf{C r}$ & $\mathbf{F e}$ & Ti \\
\hline Ti5553 & 0.14 & $<0.01$ & 5.03 & 5.10 & 5.06 & 2.64 & 0.38 & Bal. \\
\hline
\end{tabular}

Autogenous (no filler), butt welding joints of Ti5553 were obtained by LBW-CR. The conduction welds were performed using a High-Power Diode Laser (HPDL) of LABCYP, UCA (Research Group of Corrosion and Protection of University of Cádiz, Spain), model DL028S, with $2.8 \mathrm{KW}$ of maximum power acquired to ROFIN-SINAR (Plymouth, Mi, USA), shown in Figure 2. Joints were performed with treatments consisted of a linear laser scan of $35 \mathrm{~mm}$, performed at a laser power of $2.75 \mathrm{~kW}$ and a welding speed of $5 \mathrm{~mm} / \mathrm{s}$, placing the surface of the samples at the focal distance $(42 \mathrm{~mm}$ from the laser head). The spatial distribution of the laser beam source at the focal distance is included in Figure 3. The size of the spot of this laser source in this condition is $1.79 \mathrm{~mm}^{2}(1.19 \mathrm{~mm}$ in $X$ axe $\times$ $1.50 \mathrm{~mm}$ in $Y$ axe). A laboratory-made conditioning chamber, shown in Figure 4, was employed to shield the welds, allowing the application of a continuous flow of argon of $10 \mathrm{~L} / \mathrm{min}$. The laser fluence $(F)$ of these treatments was $46.21 \mathrm{~kJ} / \mathrm{cm}^{2}, F$ being estimated as Equation (1):

$$
F=\frac{P}{v D}
$$

where $F$ is the accumulated fluence (laser energy per area) of the laser treatment $\left(46.21 \mathrm{~kJ} / \mathrm{cm}^{2}\right), P$ is the Laser Power $(2.75 \mathrm{~kW}), v$ is the processing rate $(5 \mathrm{~mm} / \mathrm{s})$, and $D$ is the spot width $(1.19 \mathrm{~mm}, X$ axe).

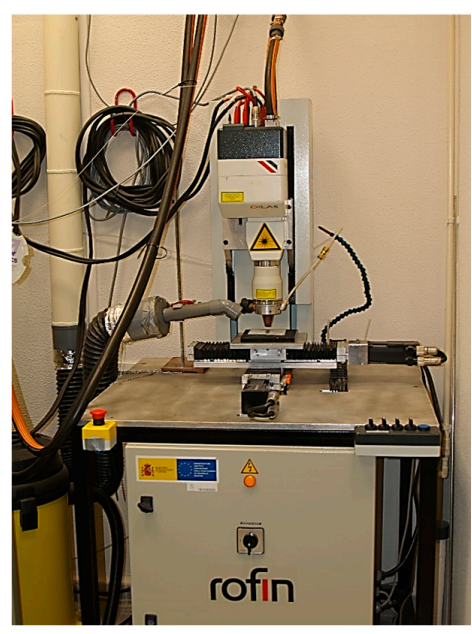

Figure 2. Equipment of High-Power Diode Laser (HPDL) employed to perform the welds under conduction regime.

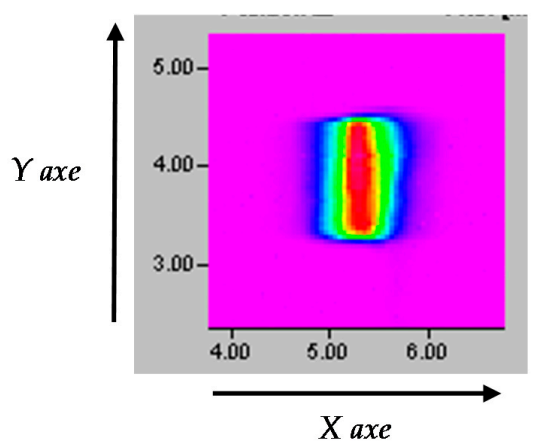

Figure 3. Spatial distribution of the laser beam source (HPDL) at the focal distance. 

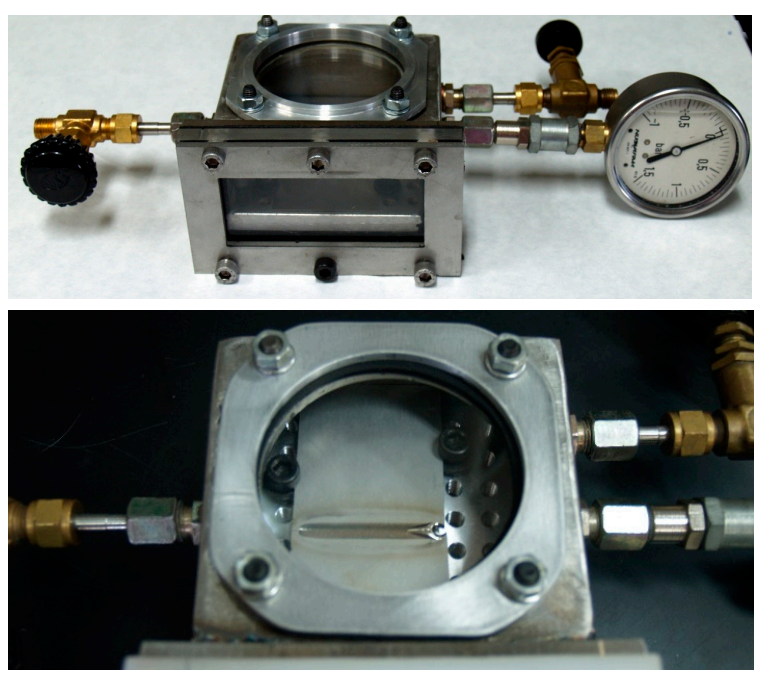

Figure 4. Laboratory-made conditioning chamber used to shield the welding samples.

The sizes of samples were $50 \times 50 \times 1.6 \mathrm{~mm}^{3}$ as shown in Figure 5. Before welding, the samples were cleaned according to ASTM B 600-91 standard. The welding direction was perpendicular to rolling direction. Metallographic samples for grain structure investigation and for hardness tests were prepared from the welded sheets (as shown in Figure 3). The metallographic preparation steps consisted of grinding from 120 to 2400 grit $\mathrm{SiC}$ paper, polishing to $0.3 \mu \mathrm{m}$ colloidal alumina, followed by final polishing with $0.05 \mu \mathrm{m}$ colloidal silica suspension. The samples were etched with Kroll's reagent with a composition of $100 \mathrm{~mL}$ water $+2 \mathrm{~mL} \mathrm{HF}+5 \mathrm{~mL} \mathrm{HNO}_{3}$. An optical microscope was used to characterize the microstructure of the welds.

Microhardness tests were carried out on the metallographically-prepared samples using a load of $300 \mathrm{~g}$ (HV300g) to produce the hardness profiles. Dog-bone flat samples (with a constant thickness of $1.6 \mathrm{~mm}$ ) were taken from the welded sheets for tensile testing, as shown in Figure 5a, in accordance with ASTM E 8M-04, with the weld located perpendicular to the tensile axis. The tensile tests were conducted at room temperature, fixing a deformation speed of $0.005 \mathrm{~mm} / \mathrm{min}$ at the elastic deformation regime, and $1.6 \mathrm{~mm} / \mathrm{min}$ at the plastic deformation regime. Finally, the fractured surfaces of tensile samples were cleaned with an ultrasonic cleaner, and subsequently examined using a Scanning Electron Microscope (SEM) at different magnifications.

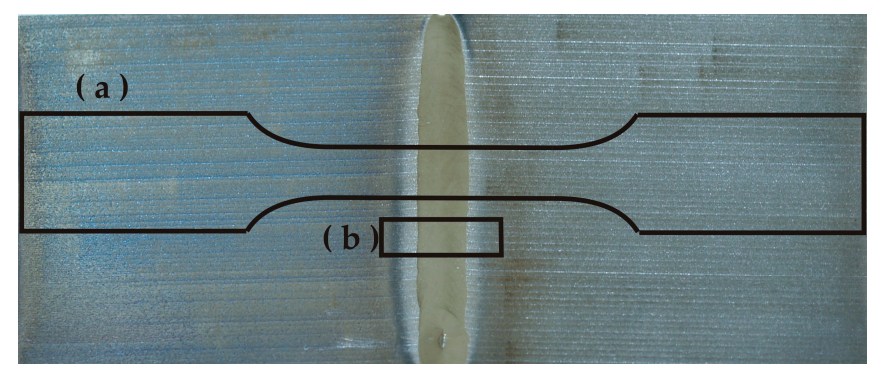

Figure 5. Schematic diagram indicating the weld joint and locations of samples for tensile tests (a) and metallographic and microhardness analysis (b).

The authors would like to clarify that welds were only made on $1.6 \mathrm{~mm}$ thick material. Future work needs to be performed to analyze the influence of the different material thickness and size on the developed microstructure and the laser fluence required to weld Ti5553 samples. This is a very important issue in LBW-CR, as the heat conduction can change when scaling the size of the welding samples. 


\section{Results and Discussion}

Macrographic images of front and back views of Ti5553-Ti5553 butt weld performed with LBW-CR are shown in Figure $6 a, b$, respectively. The absence of colored tones confirms the appropriate protection provided by the conditioning shielding system. In general, LBW allows the minimization of thermal distortion. Note that the welds seem to present an apparent deformation, related to the relative disorientation of the mechanical machining lines of samples generated before welding. In fact, the obtained welds were flat, not showing evidences of thermal distortion.

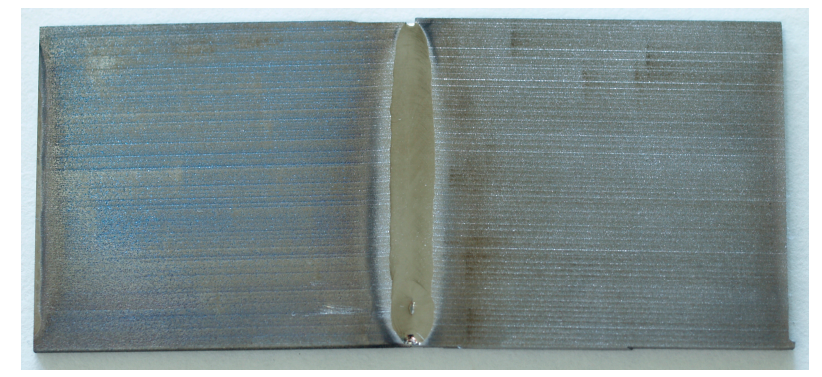

(a)

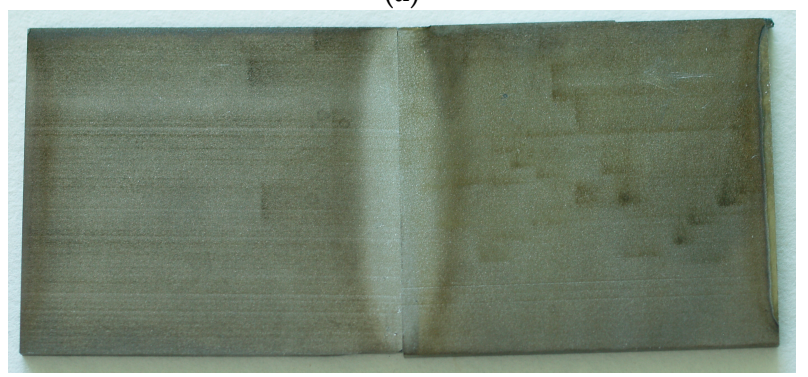

(b)

Figure 6. Front view (a) and back view (b) of Ti5553-Ti5553 butt joint performed with LBW under Conduction Regime (LBW-CR) using a HPDL.

\subsection{Microstructure and Shape of Welds}

For reference purposes, metallographic images of Ti5553 base metal (BM) are given in Figure 7a at $50 \times$ and Figure $5 b$ at $1000 \times$, showing $\alpha / \beta$ microstructure in which $\alpha$ particles with an average size of less than $5 \mu \mathrm{m}$ are distributed within the $\beta$ matrix. Cross-sections of Ti5553-Ti5553 LBW-CR butt welds were studied in detail, allowing the identification of the different zones of the weld (FZ, HAZ and BM), the analysis of the FZ morphology (shape) and the measurements of grain size at HAZ. Some metallographic images at low magnification $(50 \times)$ of the welds are reported in Figure 8 . The welds presented semicircle shape with relatively low depth/width ratio, allowing one to confirm that joints were performed under conduction regime. The shape of this LBW-CR weld can be compared with other Ti5553-Ti5553 butt welds previously obtained in the literature [31]. Thus, GTAW welds of this alloy presented V-shaped FZ, being also conduction-dominated. In contrast, the FZ for EBW and LBW performed with Nd:YAG are reported to provide hour glass-shaped welds, a morphology directly related in the literature with the keyhole regime.

Table 2 summarizes the width and depth of the FZ and HAZ of the LBW-CR welds obtained. For comparison purposes, the results obtained in recent research for Ti5553-Ti5553 butt welds performed with other technologies (GTAW, EBW and LBW-KR with Nd:YAG) [32] are also reported in the table. The widths of the FZ and the HAZ of the GTAW and LBW-CR welds were much wider compared with those of EBW and LBW-KR. The FZ generated by GTAW and LBW-CR were 5.4 and $4.9 \mathrm{~mm}$, compared with 2.6 and $1.7 \mathrm{~mm}$ made by LBW-KR and EBW, respectively. The HAZ of the GTAW and LBW-CR samples reached up to 3 and $1.3 \mathrm{~mm}$, respectively, being $0.8 \mathrm{~mm}$ for both 
LBW-KR and EBW samples. The narrower weld zones in EBW and LBW-KR samples compared with the LBW-CR and GTAW samples are associated with the higher heat source localization (smaller beam size at the focus position) of the former technologies. The microstructural characteristics of the LBW-CR welds were similar to those previously reported for other welding methods [32]: FZ with a columnar-dendritic-typed grain morphology, HAZ decorated with retained equiaxed $\beta$ grains (with larger grains at the fusion boundary and smaller grains towards BM) and epitaxial grain growth from the HAZ into the FZ.
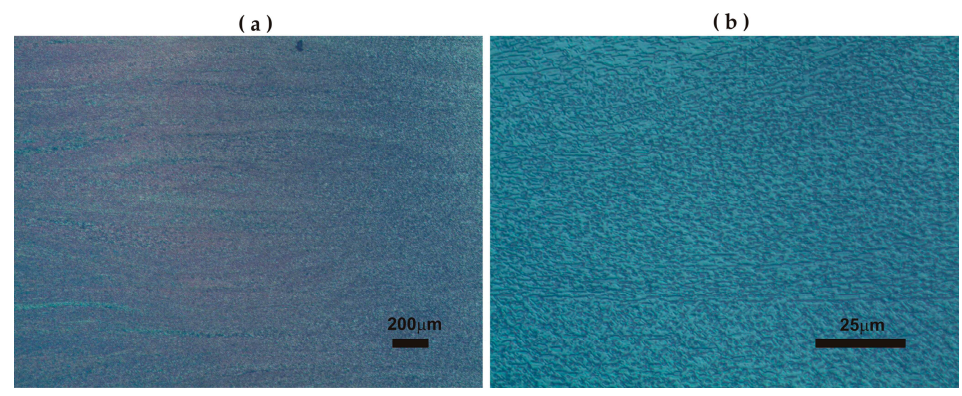

Figure 7. Metallographic images at $50 \times(\mathbf{a})$ and $1000 \times(\mathbf{b})$ of Ti5553 base metal (BM) showing the $\alpha / \beta$ microstructure ( $\alpha$ particles are the white grains).
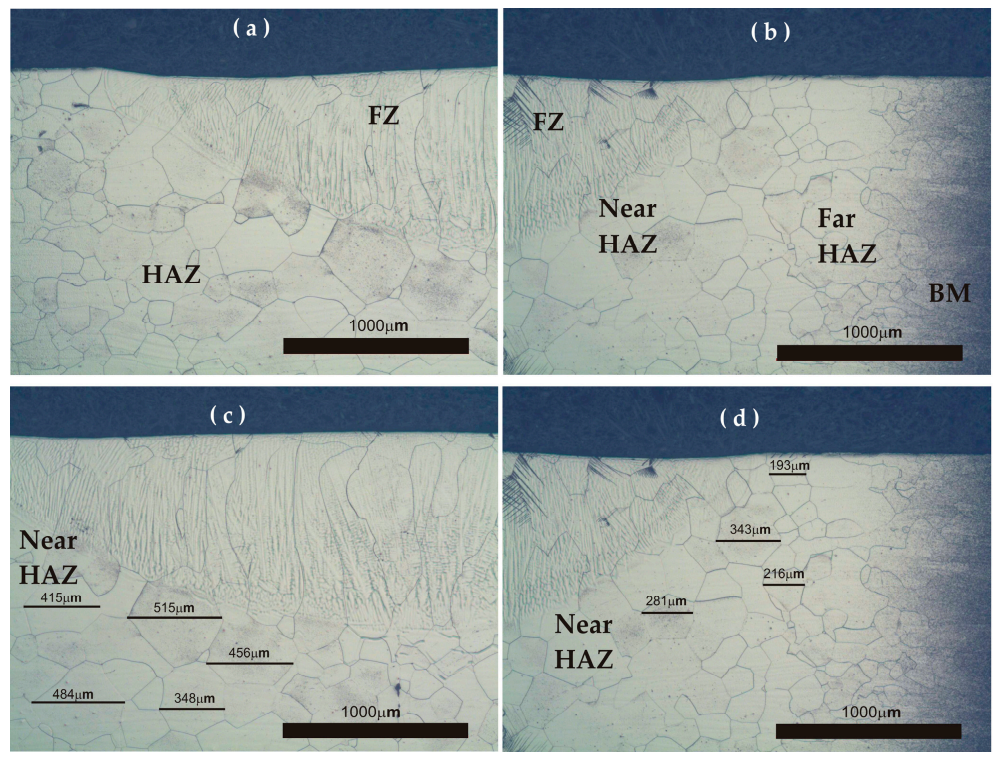

Figure 8. Metallographic images at 50× of Ti5553-Ti5553 LBW-CR butt welds showing the different zones of the welds (FZ, near HAZ, far HAZ and BM) in $(\mathbf{a}, \mathbf{b})$; and the grain size at HAZ (around $350 \mu \mathrm{m})$ in (c,d).

Table 2 also includes the averaged grain size of the welds zones. The grain sizes in the FZ for all welds were a few hundred microns. In the HAZ, large grains were observed at the near HAZ (along the fusion boundary) of up to $200 \mu \mathrm{m}$ in the EBW and LBW-Nd:YAG samples, and up to $600 \mu \mathrm{m}$ and $350 \mu \mathrm{m}$ for GTAW and LBW-HPDL samples, respectively. The grains became gradually smaller towards the BM. The larger grain sizes in the near HAZ are associated with intermediate peak temperature during welding that facilitates grain growth. Therefore, taking into account the width and grain size of the welds, it can be stated that LBW-CR is a compensated and interesting welding technology, as it employs an energy density intermediate between arc welding, such as GTAW (high heat input and low power density) and EBW/LBW-KR (relatively low heat input and high power density). 
Table 2. Width of fusion and heat-affected zone (FZ and HAZ) and grain size of HAZ of the different welds.

\begin{tabular}{cccc}
\hline Conditions & Width of FZ $(\mathbf{m m})$ & Width of HAZ $(\mathbf{m m})$ & Grain Size of HAZ $(\boldsymbol{\mu m})$ \\
\hline LBW-CR (HPDL) & 4.9 & 1.3 & 350 \\
GTAW [32] & 5.4 & 3.0 & 600 \\
LBW-KR (Nd:YAG) [32] & 2.6 & 0.8 & 200 \\
EBW [32] & 1.7 & 0.8 & 200 \\
\hline
\end{tabular}

\subsection{Microhardness}

Hardness profile of the Ti5553-Ti5553 LBW-CR butt weld is shown in Figure 9. The hardness values (HV) follow a similar tendency than those previously obtained with other welding methods [32], i.e., $290-320 \mathrm{HV}$ in the FZ, 300-360 HV in the HAZ and 370-390 HV for BM. The weld zones (FZ and HAZ) had lower hardness values compared with that of the base metal. In metastable $\beta$ titanium alloys, the hardness of the FZ is usually lower than that of the BM, as the formation of the strengthening precipitates is suppressed because of the overwhelming amount of $\beta$ stabilizing elements leading to a $[\mathrm{Mo}]_{\mathrm{eq}}$ around 12. According to Bania [33], $\alpha^{\prime}$ (alpha prime) or martensite precipitates will not form if the $[\mathrm{Mo}]_{\mathrm{eq}}$ is greater than 10. The dissolution of the $\alpha$ phase in the heat-affected zone and the presence of entirely metastable/retained $\beta$ phase in the fusion zone seem to be responsible for the significant hardness decrease in the HAZ and FZ [34]. It is interesting to note that the decrease of hardness in the FZ of LBW-CR is slightly lower than that in the FZ of welds performed with other technologies [32]. Thus, the minimum hardness value obtained in the FZ of LBW-CR weld was $310 \mathrm{HV}$, while the minimum values measured for LBW, EBW and GTAW were always below $300 \mathrm{HV}$. These results suggest that LBW-CR methodology can partially limit the dissolution of $\alpha$ phase in the FZ, keeping a slightly higher concentration of strengthening precipitates in the weld.

It is noteworthy that the hardness profiles of metastable $\beta$ titanium alloys are different than those of $\alpha$ or $\alpha / \beta$ alloys. Hardness values of $\alpha$ or $\alpha / \beta$ alloys in the weld zones are generally comparable or higher than that of the $\mathrm{BM}$, due to the formation of martensite ( $\alpha^{\prime}$ microstructure) $[10,28,35]$.

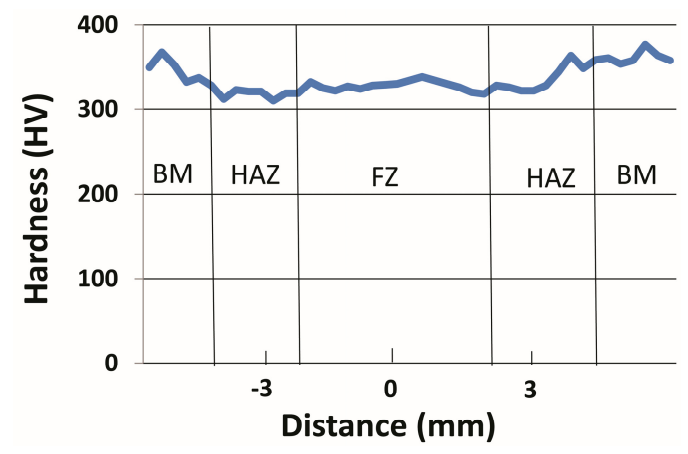

Figure 9. Hardness profile across the Ti5553-Ti5553 butt weld performed with LBW-CR with HPDL.

\subsection{Tensile Test and Fracture Surface Analysis}

Table 3 summarizes the results obtained from tensile testing of LBW-CR Ti5553-Ti5553 butt weld. It also includes the data reported in previous researches [32,36,37] for the base metal (BM), GTAW, EBW and LBW-Nd:YAG welds. Note that in [36], very low ductility (strain to rupture) values were obtained in EBW welds in comparison to [37]. The results published in [36] report the first trials to perform the EBW weld and therefore the experimental parameters were not optimised. Those results published in [37] were performed/tested with better measurement capability. All welds present a significant reduction in strengths and elongation values in comparison with the BM. The elongation of EBW and LBW-Nd:YAG welds were relatively comparable to that of the unwelded samples, while 
LBW-HPDL and GTAW welds presented lower ductility. Concerning the strength, it is interesting to highlight that the highest Ultimate Tensile Strength (UTS) values were found in LBW-HPDL welds (78\% of the BM), followed by LBW-Nd:YAG (72\% of the BM), EBW (65\% of the BM) and GTAW (56\% of the BM). In general terms, tensile properties of all these welds are in good agreement with the results previously reported by Shariff et al. [34], in which Ti5553 welds show a maximum joint efficiency of around $75 \%$ and a variable reduction of ductility.

The slightly higher UTS value obtained in the present work for LBW-CR with HPDL is thought to be due to the higher hardness of the FZ and to the lower porosity generated in the melting pool within conduction welding. In fact, conduction modes are widely claimed to provide less porous joints than keyhole as a consequence of the lower evaporation [16-21]. However, unexpected low elongation values were obtained in LBW-CR. One would expect larger ductility in LBW-CR than in LBW-KR, which provided the lower porosity and larger grains at FZ obtained in LBW-CR. The reason for this behavior is not clear for the authors, although the higher concentration of strengthening precipitates in the LBW-CR or/and the possible lower weld depth of the LBW-CR weld can be possible explanations of these low ductility results. Further investigation needs to be performed to solve this issue.

Fracture surfaces from the tensile test of LBW-CR samples are given in Figure 10. Figure 10a,b were obtained with optical microscope $(\mathrm{OM})$ at $30 \times$ and $72 \times$, respectively; and Figure $10 \mathrm{c}-\mathrm{f}$ were taken by Scanning Electron Microscope (SEM) at $300 \times($ Figure 10c) and $2000 \times$ (Figure 10d-f), respectively. Samples fractured in the weld zones, and exhibited transgranular fracture modes with microvoid coalescence (dimples) mechanism. SEM images at $2000 \times($ Figure $10 d-f)$ in different zones of the fractured samples show the dimples formation at different zones.
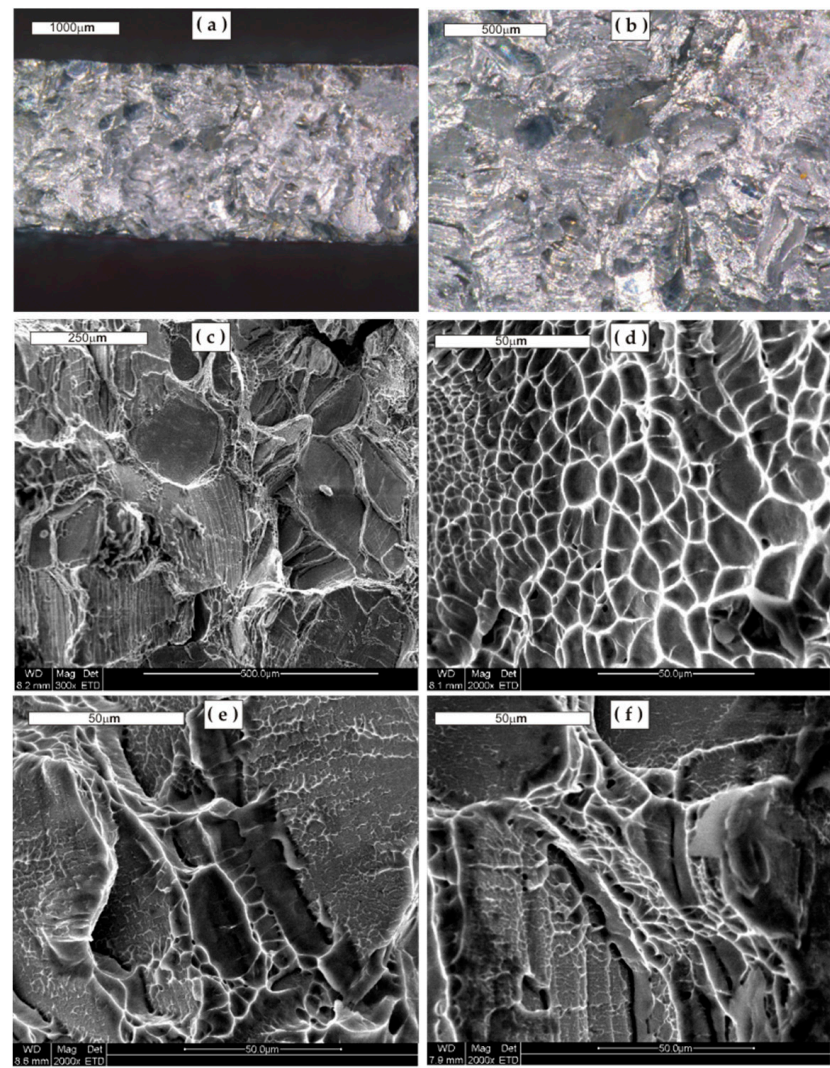

Figure 10. (a,b) Optical microscope (OM) images and (c-f) scanning electron microscope SEM images showing transgranular fracture with microvoid-coalescence mechanism of LBW-CW (HPDL) Ti5553-Ti5553 butt weld. 
Table 3. Comparison of mechanical properties of as-welded Ti5553-Ti5553 butt joints performed with LBW-CR and with other different technologies [32,36,37].

\begin{tabular}{cccc}
\hline Conditions & $\begin{array}{c}\text { Yield Strength } \\
\mathbf{( M P a )}\end{array}$ & $\begin{array}{c}\text { Ultimate Tensile } \\
\text { Strength } \mathbf{( M P a )}\end{array}$ & $\begin{array}{c}\text { Elongation (\%) } \\
\text { (Strain to Rupture) }\end{array}$ \\
\hline LBW-CR with HPDL & 816 & 818 & 3.9 \\
Base Metal [36] & 1028 & 1053 & 12 \\
EBW [36] & N/A & 778 & 0.83 \\
EBW [37] & 680 & 680 & 11 \\
LBW-KR with Nd:YAG [32] & N/A & 757 & 9 \\
GTAW [32] & N/A & 591 & N/A \\
\hline
\end{tabular}

\section{Conclusions}

Ti5553 butt welds have been obtained for the first time by means of Laser Beam Welding under Conduction Regime (LBW-CR) with a High-Power Diode Laser (HPDL). The microstructure, microhardness and strength of obtained welds have been analyzed. The welds presented a characteristic semicircle shape with relatively low depth/width ratio, a key feature of conductionlimited welding. The microstructure of LBW-CR welds was seen to be similar to those previously reported in the literature for other welding methods. Thus, the FZ presented a columnar-dendritictyped grain morphology; the HAZ is decorated with retained equiaxed $\beta$ grains (with larger grains at the fusion boundary and smaller grains towards BM); and an epitaxial grain growth is observed from the HAZ into the FZ. Interestingly, the width and grain size values of the LBW-CR welds were intermediate between the results previously obtained for GTAW and EBW. In addition, the FZ of LBW-CR presented slightly higher values of microhardness than those reported for other technologies. From the tensile tests, it is shown that the Ultimate Tensile Strength (UTS) of the welded specimens is around $78 \%$ of the BM, but still, it is slightly higher than the UTS values obtained with other joining processes, probably due to higher hardness of the FZ and to the lower porosity of the LBW-CR weld. Therefore, conduction welding offers an interesting joining mode for difficult-to-weld materials, such as metastable $\beta$ titanium alloys.

Acknowledgments: The authors (Jose Maria Sánchez-Amaya, Margarita Raquel Amaya-Vazquez, Juan De Dios Lopez-Castro, Cristina Churiaque and Francisco Javier Botana Pedemonte) would like to thank the financial support of the project SOLDATIA, Ref. TEP 6180 (Junta de Andalucía, Spain). Timotius Pasang would like to thank The Loewy Family Foundation for sponsoring his research leave at Lehigh University.

Author Contributions: Jose Maria Sánchez-Amaya conceived and designed the experiments, and wrote the paper; Margarita Raquel Amaya-Vazquez, Juan De Dios Lopez-Castro and Cristina Churiaque performed the experiments; Timotius Pasang and Yuan Tao contributed the titanium alloy and revised the paper; Francisco Javier Botana Pedemonte revised the paper.

Conflicts of Interest: The authors declare no conflict of interest.

\section{References}

1. Donachie, M.J. Titanium-A Technical Guide, 2nd ed.; ASM International: Geauga County, OH, USA, 2000; p. 70 .

2. Becker, D.W.; Baeslack, W.A., III. Property-microstructure relationships in metastable-beta titanium alloy weldments. Weld. J. Res. Suppl. 1980, 59, 85-92.

3. Liu, P.S.; Hou, K.H.; Baeslack, W.A., III; Hurley, J. Laser Welding of an Oxidation Resistant Metastable-Beta Titanium Alloy-Beta-21S. In The Minerals, Metals and Materials Society in Titanium-World Conference, Titanium '92; Froes, F.H., Caplan, I., Eds.; TMS: Pittsburgh, PA, USA, 1993; p. 1477.

4. Baeslack, W.A., III; Liu, P.S.; Barbis, D.P.; Schley, J.R.; Wood, J.R. Postweld Heat Treatment of GTA Welds in a High-Strength Metastable Titanium Alloy-Beta-CTM. In The Minerals, Metals and Materials Society in Titanium-World Conference, Titanium '92: Science and Technology; Froes, F.H., Caplan, I., Eds.; TMS: Pittsburgh, PA, USA, 1993; pp. 1469-1476. 
5. Bettaieb, M.B.; Lenain, A.; Habraken, A.M. Static and fatigue characterization of the Ti5553 titanium alloy. Fatigue Fract. Eng. Mater. Struct. 2012, 36, 401-415. [CrossRef]

6. Lütjering, G.; Williams, J.C. Titanium, 2nd ed.; Springer: New York, NY, USA, 2003; p. 330.

7. Huang, J.; Wang, Z.; Zhou, J. Cyclic Deformation Response of $\beta$-Annealed Ti-5Al-5V-5Mo-3Cr Alloy under Compressive Loading Conditions. Metall. Mater. Trans. A 2011, 42, 2868-2880. [CrossRef]

8. Fanning, J.C.; Boyer, R.R. Properties of TIMETAL 555-A New Near- Beta Alloy for Airframe Components. In Proceedings of the 10th World Conference on Titanium, Hamburg, Germany, 13-18 July 2003; Volume 4, pp. 2643-2650.

9. Leyens, C.; Peters, M. (Eds.) Titanium and Titanium Alloys: Fundamentals and Applications; Willey-VCH Verlag GmbH \& Co. KGaA: Weinheim, Germany, 2003. Available online: http://onlinelibrary.wiley.com/book/10. 1002/3527602119 (accessed on 16 June 2017).

10. Cao, X.; Kabir, A.S.H.; Wanjara, P.; Gholipour, J.; Birur, A.; Cuddy, J.; Medraj, M. Global and Local Mechanical Properties of Autogenously Laser Welded Ti-6Al-4V. Metall. Mater. Trans. A 2014, 45A, 1258-1272. [CrossRef]

11. Gouret, N.; Dour, G.; Miguet, B.; Ollivier, E.; Fortunier, R. Assessment of the Origin of Porosity in Electron-Beam-Welded TA6V Plates. Metall. Mater. Trans. A 2004, 35A, 879-889. [CrossRef]

12. Liu, J.; Ventzke, V.; Staron, P.; Schell, N.; Kashaev, N.; Huber, N. Effect of Post-weld Heat Treatment on Microstructure and Mechanical Properties of Laser Beam Welded TiAl-based Alloy. Metall. Mater. Trans. A 2014, 45A, 16-28. [CrossRef]

13. Sánchez-Amaya, J.M.; Amaya-Vázquez, M.R.; Botana, F.J. Laser welding of light metal alloys. In Handbook of Laser Welding Technologies; Katayama, S., Ed.; Elsevier: Cambridge, UK, 2013; Chapter 8; pp. 215-254.

14. Quintino, L.; Assuncao, E. Conduction Laser Welding. In Handbook of Laser Welding Technologies; Katayama, S., Ed.; Elsevier: Cambridge, UK, 2013; Chapter 6; pp. 139-162.

15. Duley, W.W. Laser Welding; John Wiley and Sons: New York, NY, USA, 1999; 264p.

16. Jin, X.; Zeng, L.; Cheng, Y. Direct observation of keyhole plasma characteristics in deep penetration laser welding of aluminum alloy 6016. J. Phys. D Appl. Phys. 2012, 45, 245205. [CrossRef]

17. Sibillano, T.; Ancona, A.; Berardi, V.; Schingaro, E.; Basile, G.; Lugarà, P.M. Optical detection of conduction/ keyhole mode transition in laser welding. J. Mater. Process. Technol. 2007, 191, 364-367. [CrossRef]

18. Pang, S.; Chen, W.; Wang, W. A Quantitative Model of Keyhole Instability Induced Porosity in Laser Welding of Titanium Alloy. Metall. Mater. Trans. A 2014, 45A, 2808-2818. [CrossRef]

19. Okon, P.; Dearden, G.; Watkins, K.; Sharp, M.; French, P. Laser welding of aluminium alloy 5083. In Proceedings of the 21st International Congress on Applications of Lasers and Electro-Optics, Scottsdale, AZ, USA, 14-17 October 2002.

20. Kabir, A.S.H.; Cao, X.; Gholipour, J.; Wanjara, P.; Cuddy, J.; Birur, A.; Medraj, M. Effect of postweld heat treatment on microstructure, hardness, and tensile properties of laser-welded Ti-6Al-4V. Metall. Mater. Trans. A 2012, 43A, 4171-4184. [CrossRef]

21. Sánchez-Amaya, J.M.; Delgado, T.; De Damborenea, J.J.; López, V.; Botana, F.J. Laser welding of AA 5083 samples by high power diode laser. Sci. Technol. Weld. Join. 2009, 14, 78-86. [CrossRef]

22. Cao, X.; Wallace, W.; Poon, C.; Immarigeon, J.P. Research and progress in laser welding of wrought aluminum alloys. I. Laser welding processes. Mater. Manuf. Process. 2003, 18, 1-22. [CrossRef]

23. Sánchez-Amaya, J.M.; Boukha, Z.; Amaya-Vázquez, M.R.; Botana, F.J. Weldability of aluminum alloys with high-power diode laser. Weld. J. 2012, 91, 155-161.

24. Cho, J.H.; Farson, D.F.; Milewski, J.O.; Hollis, K.J. Weld pool flows during initial stages of keyhole formation in laser welding. J. Phys. D Appl. Phys. 2009, 42, 175502. [CrossRef]

25. Du, H.; Hu, L.; Liu, J.; Hu, X. A study on the metal flow in full penetration laser beam welding for titanium alloy. Comput. Mater. Sci. 2004, 29, 419-427. [CrossRef]

26. Churiaque, C.; Amaya-Vazquez, M.R.; Botana, F.J.; Sánchez-Amaya, J.M. FEM Simulation and Experimental Validation of LBW under Conduction Regime of Ti6Al4V Alloy. J. Mater. Eng. Perform. 2016, 25, 3260-3269. [CrossRef]

27. Sánchez-Amaya, J.M.; Amaya-Vázquez, M.R.; Gonzalez-Rovira, L.; Botana-Galvin, M.; Botana, F.J. Influence of Surface pre-treatments on laser welding of Ti6Al4V alloy. J. Mater. Eng. Perform. 2014, 23, 1568-1575. [CrossRef] 
28. Amaya-Vázquez, M.R.; Sánchez-Amaya, J.M.; Boukha, Z.; Botana, F.J. Microstructure, microhardness and corrosion resistance of remelted TIG2 and Ti6Al4V by a high power diode laser. Corros. Sci. 2012, 56, 36-48. [CrossRef]

29. Lisiecki, A. Titanium Matrix Composite Ti/TiN Produced by Diode Laser Gas Nitriding. Metals 2015, 5, 54-69. [CrossRef]

30. Silva, D.P.; Churiaque, C.; Bastos, I.N.; Sánchez-Amaya, J.M. Tribocorrosion Study of Ordinary and Laser-Melted Ti6Al4V Alloy. Metals 2016, 6, 253. [CrossRef]

31. Astarita, A.; Rubino, F.; Carlone, P.; Ruggiero, A.; Leone, C.; Genna, S.; Merola, M.; Squillace, A. On the Improvement of AA2024 Wear Properties through the Deposition of a Cold-Sprayed Titanium Coating. Metals 2016, 6, 185. [CrossRef]

32. Pasang, T.; Sánchez-Amaya, J.M.; Tao, Y.; Amaya-Vazquez, M.R.; Botana, F.J.; Sabol, J.C.; Misiolek, W.Z.; Kamiya, O. Comparison of Ti-5Al-5V-5Mo-3Cr Welds Performed by Laser Beam, Electron Beam and Gas Tungsten Arc Welding. Procedia Eng. 2013, 63, 397-404. [CrossRef]

33. Bania, P.J. Beta Titanium Alloys in the 1990's; Eylon, D., Boyer, R.R., Koss, D.A., Eds.; TMS: Warrendale, PA, USA, 1993; pp. 3-14.

34. Shariff, T.; Cao, X.; Chromik, R.R.; Baradari, J.G.; Wanjara, P.; Cuddy, J.; Birur, A. Laser welding of Ti-5Al-5V-5Mo-3Cr. Can. Metall. Q. 2011, 50, 263-272. [CrossRef]

35. Caiazzo, F.; Alfieri, V.; Corrado, G.; Argenio, P.; Barbieri, G.; Acerra, F.; Innaro, V. Laser Beam Welding of a Ti-6Al-4V Support Flange for Buy-to-Fly Reduction. Metals 2017, 7, 183. [CrossRef]

36. Mitchell, R.; Short, A.; Pasang, T.; Littlefair, G. Characteristics of Electron Beam Welded Ti and Ti Alloys. Adv. Mater. Res. 2011, 275, 81-84. [CrossRef]

37. Sabol, J.C.; Pasang, T.; Misiolek, W.Z.; Williams, J.C. Localized tensile strain distribution and metallurgy of electron beam welded Ti-5Al-5V-5Mo-3Cr titanium alloys. J. Mater. Process. Technol. 2012, 212, 2380-2385. [CrossRef]

(C) 2017 by the authors. Licensee MDPI, Basel, Switzerland. This article is an open access article distributed under the terms and conditions of the Creative Commons Attribution (CC BY) license (http:/ / creativecommons.org/licenses/by/4.0/). 